\title{
Migraine patients' journey until a tertiary headache center: an observational study
}

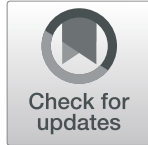

\author{
Mario Fernando Prieto Peres ${ }^{1 *}$ (D), Diego Belandrino Swerts' ${ }^{2}$, Arão Belitardo de Oliveira ${ }^{3}$ and \\ Raimundo Pereira Silva-Neto ${ }^{4}$
}

\begin{abstract}
Background: Migraine diagnosis is based on clinical aspects and is dependent on the experience of the attending physician. This study aimed to describe the patients journey profile until they start their experience in a tertiary headache center.

Methods: In a cross-sectional study, medical charts from migraine patients were reviewed to describe which treatments, procedures and follow-up strategies are performed until the first appointment with a headache specialist. Patients from both sexes, $\geq 18$ years old, which came to their first visit from March to July 2017 were included. Sociodemographic information, headache characteristics, diagnostic methods previously used, clinical history, family history and the treatments previously used were assessed in the first appointment with a specialist. Patient Health Questionnaire-9 and General Anxiety Disorder-7 were also applied. Descriptive analyses were performed to describe the sample profile and statistical tests were used to evaluate factors associated with the type of migraine (chronic or episodic).
\end{abstract}

Results: The sample consisted of 465 patients. On average, the pain started 17.1 (SD $=11.4$ ) years before the first appointment with a headache specialist. Most of patients were classified as having chronic migraine (51.7\%), with an average frequency of $15.5(\mathrm{SD}=9.9)$ days per month. Regarding patients' journey until a specialist, most patients were submitted to laboratory tests (74.0\%), cranial tomography (66.8\%) and magnetic resonance imaging (66.8\%) as diagnostic methods, and preventive drugs (70.2\%) and acupuncture (61.0\%) as treatments. After stratification by migraine type as episodic or chronic, patients with chronic migraine were submitted to more magnetic resonance imaging test, acupuncture, psychotherapy, used preventive drugs, and reported to have used topiramate without beneficial effects.

Conclusions: Brazilian patients with migraine experiment a long journey until getting to a headache specialist and are submitted to a great number of unnecessary exams, especially those with chronic migraine.

Keywords: Migraine disorders, Burden, delayed diagnosis, Tertiary healthcare, Time-to-treatment

\section{Background}

Headache is one of the leading causes of need for medical care, according to the World Health Organization (WHO) [1]. Estimated worldwide prevalence is in average $12 \%$ and in countries from Central and South America, 16\% [2]. In Brazil, the prevalence estimates may vary with the type of headache from $15.2 \%$ for migraine to $70.6 \%$, for any headache type [3].

\footnotetext{
* Correspondence: mariop3r3s@gmail.com

${ }^{1}$ Hospital Israelita Albert Einstein, São Paulo, Brazil. Instituto de Psiquiatria,

Hospital das Clínicas da Faculdade de Medicina da USP, Rua Joaquim

Eugênio de Lima, 881 cj 708, Sao Paulo, SP, Brazil

Full list of author information is available at the end of the article
}

Migraine is characterized by recurrent attacks of moderate to severe, usually with pulsatile and unilateral headache, and is one of the most disabling diseases [4]. It is a multifactorial disease, with genetic, endogenous and environmental factors. Frequency may vary from episodic to a daily basis [5]. Chronic migraine is defined by the occurrence of episodes of headache in at least 15 days per month, for at least three months, and the pain has characteristics of migraine (unilateral aspect, pulsatile, moderate or severe pain, presence or absence of aura, and others) in at least eight days per month $[6,7]$. Chronic migraine is significantly associated with highest 
degree of disabilities when compared with episodic migraine [8].

Although migraine sufferers experience often disable headaches, a significant proportion never consulted a physician, general practitioner, neurologist or a tertiary headache specialist $[9,10]$. Disease burden elevates with poor health care access.

More attention has been given lately to the patient journey as an attempt to improve health care quality [11]. But limited information is available on the journeys patients take before reaching one tertiary headache center [12]. In the UK, 200 patients were studied on their first attendance at a headache clinic. Most patients had not been given a formal diagnosis in primary care, and only a few patients had been offered triptans [13]. In a similar pattern, an Italian survey has shown that more than $70 \%$ of patients receive the diagnosis of migraine when attending to a headache center and only $26.8 \%$ had a previous diagnosis of the condition [14].

We aimed to describe in this study the patients journey profile until they start their experience in a tertiary headache center, so we could deeply understand patients need, improving headache specialized care.

\section{Methods}

\section{Study design}

This was a single-center, observational, cross-sectional study conducted in order to describe which treatment, procedures and any follow-up strategies migraine patients in Brazil have performed until the first appointment with a headache specialist in a tertiary center. Information were extracted from medical charts of patients who answered to an interview during the first medical visit at the study site. The study was conducted in accordance with local laws. Since it was a crosssectional study conducted by medical charts review, without subjects' identification, there was no need to sign an informed consent.

\section{Eligibility criteria}

Medical charts from adult patients from both sexes, 18 years old or higher, who came to their first visit in a tertiary headache center, in Sao Paulo (Sao Paulo Headache Center), were included in the analysis, from March to July 2017. Exclusion criteria were: men or women below the age of 18 , patients with associated dementia, or significant neurological deficit.

\section{Study procedures}

At Sao Paulo Headache Center patients are usually submitted to an interview during the first routine visit. The questionnaire contains questions on patients' sociodemographic information, headache characteristics, diagnostic methods previously used, clinical history, family history and treatments previously used. Two standardized instruments are used: Patient Health Questionnaire-9 (PHQ-9) and General Anxiety Disorder-7 (GAD-7).

PHQ-9 is composed by nine questions to assess the severity of depression through the presence of the following symptoms in the past two weeks: depressed mood, anhedonia, having trouble sleeping, feeling tired, change in appetite or weight, feelings of guilt and worthlessness, having trouble concentrating, feeling slowed down or restless, and having suicidal thoughts. The answers are given in a 4-point Likert scale in which patients chose between "not at all", "several days", "more than half the days" and "nearly every day". Final scores are calculated through the sum of each answer and stratified in five groups of depression severity (minimal or none: $0-4$; mild: $5-9$; moderate: $10-14$; moderately severe: 15-19; severe: 20-27) [15].

GAD-7 is an instrument used for assessment, diagnosis and monitoring of anxiety. It is composed by seven items, disposed in a 4-point Likert scale (0: not at all; 3: nearly every day). Final scores are calculated through the sum of each answer and stratified into four severity groups (minimal/no anxiety: 0-4; mild: 5-9; moderate: 10-14; severe: 15-21) [16].

\section{Statistical analysis}

A descriptive analysis was performed to describe the sample profile. Measures of central tendency and dispersion were used for numerical variables and measures of frequency for categorical variables.

Chronic and episodic migraine were defined based on the International Classification of Headache Disorders [7]. In order to evaluate factors associated with the type of migraine (chronic or episodic) statistical tests were performed. Categorical variables' association was assessed using the Chi Square test. Numeric variables relationship was assessed using $\mathrm{T}$ test (variable with normal distribution) or Mann-Whitney (variable without normal distribution) test. The data normality was identified by ShapiroWilk test. Statistically significant results were tabulated. A significance level of $5 \%$ was adopted and the analyses were performed in statistical software R Project Version 3.5.1.

\section{Results \\ Patients' profile}

The sample consisted of 465 patients and their profile is shown in Table 1. Of the total sample, $72.7 \%$ were women, $58.9 \%$ were married and $37.8 \%$ were employed. Mean age was 37.3 years old $(S D=13.0)$ and Body Mass Index $24.1(\mathrm{SD}=3.9)$.

Through PHQ-9 analysis, $68.4 \%$ of patients were classified with minimal/none or mild depression. GAD-7 results showed $63.6 \%$ of patients classified as having no symptoms or mild symptoms. 
Table 1 Sociodemographic and clinical characteristics of patients

\begin{tabular}{|c|c|c|}
\hline Sociodemographic and clinical data & $\mathrm{N}$ & $\%$ \\
\hline \multicolumn{3}{|l|}{ Gender $(n=462)$} \\
\hline Men & 126 & 27.3 \\
\hline Women & 336 & 72.7 \\
\hline \multicolumn{3}{|l|}{ Marital status $(n=241)$} \\
\hline Married & 142 & 58.9 \\
\hline Single & 79 & 32.8 \\
\hline Divorced & 16 & 6.6 \\
\hline Widower & 3 & 1.2 \\
\hline Separated & 1 & 0.4 \\
\hline \multicolumn{3}{|l|}{ Activity/main occupation $(n=230)$} \\
\hline Employed & 176 & 76.5 \\
\hline Student & 37 & 16.1 \\
\hline Housewife & 14 & 6.1 \\
\hline Retired & 2 & 0.9 \\
\hline Unemployed & 1 & 0.4 \\
\hline Age $($ Mean/SD $-n=463)$ & 37.3 & 13.0 \\
\hline BMI (Mean/SD - $n=334)$ & 24.1 & 3.9 \\
\hline \multicolumn{3}{|c|}{ Patient Health Questionnaire - 9 (PHQ-9) $(n=445)$} \\
\hline Minimal or none & 152 & 34.2 \\
\hline Mild & 152 & 34.2 \\
\hline Moderate & 75 & 16.9 \\
\hline Moderately severe & 35 & 7.9 \\
\hline Severe & 31 & 7.0 \\
\hline \multicolumn{3}{|c|}{ General Anxiety Disorder $-7(G A D-7)(n=445)$} \\
\hline None & 139 & 31.2 \\
\hline Mild & 144 & 32.4 \\
\hline Moderate & 93 & 20.9 \\
\hline Severe & 69 & 15.5 \\
\hline \multicolumn{3}{|l|}{ Health problems $(n=355)$} \\
\hline Rhinitis & 180 & 50.7 \\
\hline Sinusitis & 175 & 49.3 \\
\hline Gastritis & 173 & 48.7 \\
\hline Kidney Stone & 66 & 18.6 \\
\hline Polycystic ovary & 58 & 16.3 \\
\hline Systemic arterial hypertension & 39 & 11.0 \\
\hline Endometriosis & 22 & 6.2 \\
\hline Fibromyalgia & 21 & 5.9 \\
\hline \multicolumn{3}{|c|}{ Family member who also had a history of headache $(n=207)$} \\
\hline Mother & 118 & 57.0 \\
\hline Siblings & 71 & 34.3 \\
\hline Grandparents & 53 & 25.6 \\
\hline Father & 49 & 23.7 \\
\hline Children & 25 & 12.1 \\
\hline
\end{tabular}

SD Standard deviation
The three main health problems reported by the patients were rhinitis (38.7\%), sinusitis (37.6\%) and gastritis (37.2\%). The most frequently reported family member who also had a history of headache was mother (25.4\%).

Headache characteristics are presented in Table 2. On average, patients reported the beginning of pain 17.1 $(\mathrm{SD}=11.4)$ years before the interview, attack duration of $53.7(\mathrm{SD}=62.0)$ hours and a pain intensity of 6.8 in a 0 10 scale. Most cases were classified as chronic migraine (51.7\%). Mean headache frequency was $15.5(\mathrm{SD}=9.9)$ days per month. Furthermore, $29.9 \%$ of the patients reported migraine with aura.

In $59.3 \%$ of patients, headache location was unilateral. Regarding pain location, ocular region was the most reported (51.7\%), followed by temporal (48.7\%) and frontal (44.4\%). Throbbing type headache was described in $71.3 \%$ of patients.

\section{Patients' journey until specialist}

Laboratory tests (74.0\%), computerized tomography (66.8\%) and magnetic resonance imaging (66.8\%) were previously used as diagnostic methods by more than half of patients (Table 3).

Regarding treatments previously prescribed to patients, the most frequently used were preventive drugs and acupuncture, in $70.2 \%$ and $61.0 \%$ of patients, respectively. Other reported treatments were: psychotherapy $(n=178$; 48.2\%); physiotherapy ( $n=129 ; 36.4 \%)$; anesthetic blockages $(n=91 ; 26.1 \%)$; meditation $(n=75 ; 21.1 \%)$; botulinum toxin $(n=67 ; 19.1 \%)$; and biofeedback $(n=4$; 1.2\%) (Table 4).

Patients' experiences using preventive drugs and triptans/ergotamines are shown in Tables 5 and 6 , respectively.

Regarding preventive drugs, excluding patients who have not used the medication for a long time, all drugs were classified as "without beneficial effect" and "with beneficial effect, but with side effects". Citalopram was classified as without beneficial effect by 14 of 17 patients (82.4\%). In addition, flunarizine, melatonin and nortriptyline were reported with negative results, classified as without beneficial effects by $77.8 \%, 75.0 \%$ and $73.2 \%$ of the cases, respectively (Table 5). Of the 465 patients, 115 (24.7\%) were using preventive drug at moment of information collection.

About triptans/ergotamines used, sumatriptan succinate was the most effective drug $(37.6 \%$ of the patients reporting a good effect), followed by rizatriptan (32.9\%) and naratriptan hydrochloride (26.3\%). The combination of dihydroergotamine mesylate, paracetamol, caffeine, and metoclopramide hydrochloride presented the worst evaluation, with $62.2 \%$ of reports as 'does not work', $29.4 \%$ of 'regular effect or might not work' and only $8.4 \%$ of 'good effect'. 
Table 2 Headache characteristics reported by patients

\begin{tabular}{|c|c|}
\hline Headache characteristics & $\mathrm{N}$ \\
\hline History of Headache in Years (Mean/SD - $n=459$ ) & 17.1 \\
\hline Pain intensity $(0-10)($ Mean/SD $-n=464)$ & 6.8 \\
\hline Mean attack duration (hours) (Mean/SD - $n=216$ ) & 53.7 \\
\hline $\begin{array}{l}\text { Mean headache frequency per month (days) } \\
\text { (Mean/SD }-n=464 \text { ) }\end{array}$ & 15.5 \\
\hline Episodic migraine (up to 14 days) & 224 \\
\hline Chronic migraine (15 or more days) & 240 \\
\hline \multicolumn{2}{|l|}{ Migraine with aura $(n=448)$} \\
\hline Yes & 134 \\
\hline No & 314 \\
\hline \multicolumn{2}{|l|}{ Time of pain onset $(n=464)$} \\
\hline Morning & 307 \\
\hline Afternoon & 310 \\
\hline Night & 280 \\
\hline Dawn & 140 \\
\hline \multicolumn{2}{|l|}{ Head side affected by pain $(n=464)$} \\
\hline Bilateral & 189 \\
\hline Unilateral/alternating & 179 \\
\hline Only left side & 50 \\
\hline Only right side & 46 \\
\hline \multicolumn{2}{|l|}{ Pain location $(n=464)$} \\
\hline Ocular & 240 \\
\hline Temporal & 226 \\
\hline Frontal & 206 \\
\hline Occipital & 201 \\
\hline Parietal & 187 \\
\hline Vertex & 120 \\
\hline Neck & 110 \\
\hline \multicolumn{2}{|l|}{ Type of pain $(n=464)$} \\
\hline Throbbing & 331 \\
\hline Dull/Aching & 226 \\
\hline Others & 29 \\
\hline
\end{tabular}

SD Standard deviation

The study sample was stratified by the type of migraine, episodic or chronic, to assess association with several characteristics of patients' journey. Table 7 shows those who had statistically significant results. Patients with chronic migraine were submitted to more magnetic resonance imaging test, acupuncture, psychotherapy, preventive drugs, and reported to have used topiramate without beneficial effects. The use of anesthetic blockages was more frequent among patients with episodic migraine.

\section{Discussion}

This study was conducted with the primary aim to describe the journey of patients with migraine in a tertiary
Table 3 Previous methods of diagnosis reported by patients

\begin{tabular}{lll}
\hline Previous methods of diagnosis & $\mathrm{N}$ & $\%$ \\
\hline Tests $(n=392)$ & & \\
Laboratory tests & 290 & 74.0 \\
Cranial tomography & 262 & 66.8 \\
Magnetic resonance imaging & 262 & 66.8 \\
Electroencephalogram & 163 & 41.6 \\
Others & 21 & 5.4 \\
\hline
\end{tabular}

headache center in Sao Paulo, Brazil until their first appointment. In order to answer this objective, medical charts from patients who attended to a tertiary headache center were reviewed, collecting information about patients' history registered in the first attendance. As main results, diagnostic methods, treatments and preventive strategies previously used by patients were reported.

More than half of patients reported to have previously performed laboratory tests, cranial tomography and magnetic resonance imaging. However, guidelines do not recommend the use of any medical exams for migraine diagnosis [17-19]. The use of unnecessary strategies to investigate signs and symptoms may have different impacts, especially for patients, such as the exposure radiation present in tomography and magnetic resonance imaging. Viana et al. (2016) have shown that most patients also perform a great number of unnecessary exams, of which $40 \%$ includes radiation exposure [20].

Regarding treatments previously performed, most patients used preventive drugs and acupuncture. The use of preventive drugs is in accordance with several guidelines which state that the cure is not the aim of migraine management. We have not listed the option of effective treatment without side effects. The medication list refers to previous experiences, we believe patients experiencing effective treatments without side effects are less likely to reach a tertiary headache center, or they may be fitting into the "I have not used for a long time" category. Especially in cases of chronic disease, treatment has the objective to reduce frequency and intensity of crises [17-19]. The use of alternative therapies is not recommended due the lack of evidence on its efficacy in migraine treatment. Only acupuncture has shown satisfactory results when compared to topiramate in a clinical trial and is recommended by the Latin American consensus for the treatment of chronic migraine [21, 22]. Thus, although prescribed by nonspecialized assistance, the treatment seems to be in accordance with recommendations.

Vincent and colleagues (1999) have previously reported the primary headache care delivered by nonspecialists in Brazil. In order to assess this objective, the study interviewed 414 patients with questions such as the duration of headache, the need for medical assistance, types of diagnoses provided by nonspecialists, the sort of investigations 
Table 4 Patients' experience with non-pharmacological treatments

\begin{tabular}{|c|c|c|c|c|c|c|c|c|}
\hline \multirow{2}{*}{$\begin{array}{l}\text { Treatments }(n=423) \\
\text { Acupuncture }(n=382)\end{array}$} & \multicolumn{2}{|c|}{ Never used } & \multicolumn{2}{|c|}{ Currently used } & \multicolumn{2}{|c|}{ I did it without succeed } & \multicolumn{2}{|c|}{ I did it with good results } \\
\hline & 149 & 39.0 & 40 & 10.5 & 129 & 33.8 & 64 & 16.8 \\
\hline Psychotherapy $(n=369)$ & 191 & 51.8 & 67 & 18.2 & 52 & 14.1 & 59 & 16.0 \\
\hline Physiotherapy $(n=354)$ & 225 & 63.6 & 22 & 6.2 & 48 & 13.6 & 59 & 16.7 \\
\hline Botulinum toxin $(n=350)$ & 283 & 80.9 & 9 & 2.6 & 30 & 8.6 & 28 & 8.0 \\
\hline Preventive drugs $(n=386)$ & 115 & 29.8 & 90 & 23.3 & 124 & 32.1 & 57 & 14.8 \\
\hline Anesthetic blockages ( $n=349$ ) & 258 & 73.9 & 24 & 6.9 & 41 & 11.7 & 26 & 7.4 \\
\hline Biofeedback $(n=333)$ & 329 & 98.8 & 2 & 0.6 & - & - & 2 & 0.6 \\
\hline Meditation $(n=355)$ & 280 & 78.9 & 23 & 6.5 & 29 & 8.2 & 23 & 6.5 \\
\hline
\end{tabular}

and treatments prescribed. Patients reported that had seen on average 3 health assistants before the appointment with a specialist and a headache beginning on average 11 years before. As observed in the present study, patients performed a great number of investigative procedures, such as electroencephalography, computerized tomography, and sinus and skull x-rays. Regarding prescribed treatment, a prophylactic strategy was adopted by $48.9 \%$ of migraine patients, involving benzodiazepines, tricyclic antidepressants, beta-blockers, flunarizine, anticonvulsants, pizotifen and nonpharmacologic strategies such as use of new glasses, diet and homeopathic treatment [23]. These data are consistent with those presented in this study, showing that migraine patients are benefited from specialized care and that misdiagnosis is still observed twenty years later. Furthermore, data suggests the use of a large amount of unnecessary health resources by migraine patients, generating burden to both, patients and society. The need for conduction of a study estimating economic burden of migraine in Brazil, to assess the real impact of these practices, is highlighted.

Patients' experience about drugs used in the treatment and as a preventive approach was assessed, describing how they classify medicines regarding their efficacy and the occurrence of side effects. Preventive drugs were classified by patients as without beneficial effects or when the beneficial effects are observed, side effects are also reported. The preference of Brazilian patients for migraine preventive therapy was previously assessed and the effectiveness was the most important aspect of the treatment by $92.7 \%$ of the sample. The occurrence of adverse events was the third of seven aspects in the classification of most important, by $32.4 \%$ of the patients [24]. These data reinforce the need for investment in technologies that combine both effectiveness and safety, which are of great concern of migraine patients.

The sample was further stratified by the type of migraine, as episodic or chronic. The prescription of magnetic resonance imaging test, acupuncture, psychotherapy, use of preventive drugs and use of topiramate without beneficial effects was most likely to be observed among those with chronic disease. The use of anesthetic blockages was more frequent among patients with episodic disease. To date, this is the first study to assess differences in the treatment performed before the attendance with specialist comparing patients with

Table 5 Patients' experience with preventive drugs

\begin{tabular}{|c|c|c|c|c|c|c|c|c|}
\hline \multirow[t]{2}{*}{$\begin{array}{l}\text { Preventive medicines } \\
(n=465)\end{array}$} & \multicolumn{2}{|c|}{$\begin{array}{l}\text { I have not used it for } \\
\text { a long time }\end{array}$} & \multicolumn{2}{|c|}{$\begin{array}{l}\text { I have already used it without } \\
\text { beneficial effect }\end{array}$} & \multicolumn{2}{|c|}{$\begin{array}{l}\text { I have already used it with beneficial } \\
\text { effect but with side effects }\end{array}$} & \multicolumn{2}{|c|}{ Never used } \\
\hline & $\overline{\mathrm{N}}$ & $\%$ & $\bar{N}$ & $\%$ & $\bar{N}$ & $\%$ & $\bar{N}$ & $\%$ \\
\hline Topiramate & 49 & 28.8 & 75 & 44.1 & 75 & 44.1 & 295 & 63.4 \\
\hline Divalproate & 28 & 31.5 & 48 & 53.9 & 18 & 20.2 & 376 & 80.9 \\
\hline Propranolol, Atenolol, Nadolol & 36 & 31.3 & 54 & 47.0 & 26 & 22.6 & 350 & 75.3 \\
\hline Melatonin & 38 & 49.4 & 30 & 39.0 & 10 & 13.0 & 388 & 83.4 \\
\hline Amitriptyline & 32 & 33.3 & 46 & 47.9 & 22 & 22.9 & 369 & 79.4 \\
\hline Nortriptyline & 29 & 30.9 & 52 & 55.3 & 19 & 20.2 & 371 & 79.8 \\
\hline Flunarizine & 28 & 45.2 & 28 & 45.2 & 8 & 12.9 & 403 & 86.7 \\
\hline Fluoxetine & 31 & 35.2 & 35 & 39.8 & 25 & 28.4 & 377 & 81.1 \\
\hline Sertraline & 24 & 42.1 & 22 & 38.6 & 11 & 19.3 & 408 & 87.7 \\
\hline Venlafaxine & 23 & 38.3 & 23 & 38.3 & 15 & 25.0 & 405 & 87.1 \\
\hline Desvenlafaxine & 25 & 64.1 & 9 & 23.1 & 5 & 12.8 & 426 & 91.6 \\
\hline
\end{tabular}


Table 6 Patients' experience with triptans/ergotamines

\begin{tabular}{|c|c|c|c|c|c|c|c|c|}
\hline & \multicolumn{2}{|c|}{ Does not work } & \multicolumn{2}{|c|}{$\begin{array}{l}\text { Has regular effect/ } \\
\text { Does not always } \\
\text { work }\end{array}$} & \multicolumn{2}{|c|}{ Has good effect } & \multicolumn{2}{|c|}{ Never used } \\
\hline & $\mathrm{N}$ & $\%$ & $\mathrm{~N}$ & $\%$ & $\mathrm{~N}$ & $\%$ & $\mathrm{~N}$ & $\%$ \\
\hline Naratriptan hydrochloride & 51 & 28,5 & 81 & 45,3 & 47 & 26,3 & 286 & 61,5 \\
\hline Zolmitriptan & 28 & 44,4 & 20 & 31,7 & 15 & 23,8 & 402 & 86,5 \\
\hline Rizatriptan benzoate & 27 & 35,5 & 24 & 31,6 & 25 & 32,9 & 389 & 83,7 \\
\hline Sumatriptan succinate & 55 & 32,4 & 51 & 30,0 & 64 & 37,6 & 295 & 63,4 \\
\hline Dihydroergotamine mesylate + dipyrone monohydrate + caffeine & 65 & 48,9 & 47 & 35,3 & 21 & 15,8 & 332 & 71,4 \\
\hline $\begin{array}{l}\text { Dihydroergotamine mesylate + paracetamol + caffeine + } \\
\text { metoclopramide hydrochloride }\end{array}$ & 74 & 62,2 & 35 & 29,4 & 10 & 8,4 & 346 & 74,4 \\
\hline
\end{tabular}

different types of migraine. When resource utilization is compared, chronic migraine patients seems to report more visits to general practitioners, neurologists, nurse and physician assistant, diagnostic testing and other exams and the use of drugs [25]. So, the journey of patients, stratified by the type of migraine, still needs to be further addressed by other studies to confirm the associations found.

Other outcomes were reported by the study, including the presence of anxiety and depression, through the standardized instruments GAD-7 and PHQ-9. A greater frequency of anxiety was observed when compared with depression symptoms, once $68.8 \%$ of patients presented some level of anxiety and 66\%, some level of depression. This result corroborates the association between anxiety and migraine, more robust than depression, as reported in a Brazilian study recently published [26]. Other results such as sociodemographic characteristics are consistent with those published in the country [26, 27].
Although international guidelines states that most primary and medication-overuse headaches may be adequately managed on primary healthcare, the same reports also highlight the cases where referral to a specialist is necessary [28]. This need for referral is reinforced by data shown in the present study.

Important to add the referral pattern, as previous migraine diagnosis. Patients come to our headache center by self-referral, and the vast majority had already a migraine diagnosis.

This study has several limitations, specially related to the source of information. When using information from medical charts, data is dependent on the quality of registration which may compromise the available reports. Another limitation is the retrospective nature of the interview, in which patients were asked to remember all the procedures previously performed. However, this study adds important knowledge about treatment of migraine in Brazil.

Table 7 Characteristics of patients' journey significantly associated with the type of migraine

\begin{tabular}{|c|c|c|c|c|c|c|}
\hline & & \multicolumn{4}{|c|}{ Migraine } & \multirow[t]{3}{*}{$p$-value } \\
\hline & & \multicolumn{2}{|c|}{ Episodic } & \multicolumn{2}{|c|}{ Chronic } & \\
\hline & & $\overline{\mathrm{N}}$ & $\%$ & $\overline{\mathrm{N}}$ & $\%$ & \\
\hline \multirow[t]{2}{*}{ Test - Magnetic resonance imaging } & No & 116 & 51.8 & 86 & 35.8 & 0.001 \\
\hline & Yes & 108 & 48.2 & 154 & 64.2 & \\
\hline \multirow[t]{2}{*}{ Treatment - Acupuncture } & No & 88 & 47.8 & 61 & 30.8 & 0.001 \\
\hline & Yes & 96 & 52.2 & 137 & 69.2 & \\
\hline \multirow[t]{2}{*}{ Treatment - Psychotherapy } & No & 104 & 57.8 & 87 & 46.0 & 0.031 \\
\hline & Yes & 76 & 42.2 & 102 & 54.0 & \\
\hline \multirow[t]{2}{*}{ Treatment - Preventive medicines } & No & 73 & 39.2 & 42 & 21.0 & $<0.001$ \\
\hline & Yes & 113 & 60.8 & 158 & 79.0 & \\
\hline \multirow[t]{2}{*}{ Treatment - Anesthetic blockages } & No & 136 & 81.9 & 122 & 66.7 & 0.002 \\
\hline & Yes & 30 & 18.1 & 61 & 33.3 & \\
\hline \multirow[t]{3}{*}{ Preventive drug - Topiramate } & I have not used it for a long time & 25 & 41.0 & 24 & 23.1 & 0.001 \\
\hline & I have already used it without beneficial effect & 14 & 23.0 & 56 & 53.8 & \\
\hline & I have already used it with beneficial effect but with side effects & 22 & 36.1 & 24 & 23.1 & \\
\hline
\end{tabular}




\section{Conclusion}

Brazilian patients with migraine experiment a long journey until getting to a headache specialist, which may last on average 17 years since the first headache episode. These patients are submitted to a great number of unnecessary exams, although diagnosis of migraine may be performed only based on clinical examination and the evaluation of patients' history. However, the treatment performed by non-specialists seems to be consistent with that proposed by guidelines. When migraine patients are stratified in chronic and episodic cases, the use of unnecessary technologies is still greater in those with chronic disease.

This study reinforces the need of a specialized assistance for migraine patients, so patients have more assertive treatment, improving impact of the disease and quality of life.

\section{Acknowledgements}

We thank SENSE Company Brazil for editorial support in developing drafts of this manuscript. The authors were responsible for critical revisions of the manuscript for important intellectual content.

\section{Authors' contributions}

MFPP conceived the original idea and developed the theoretical framework. All authors contributed to the interpretation of the results. All authors discussed the results and contributed to the final version of the manuscript. All authors read and approved the final manuscript.

\section{Funding}

The study had no funding.

\section{Availability of data and materials}

Data is available upon reasonable request and with permission of Sao Paulo Headache Center.

\section{Ethics approval and consent to participate}

The study was conducted in accordance with local laws. Since it was a crosssectional study conducted by medical charts review, without subjects' identification, there was no need to sign an informed consent.

\section{Consent for publication}

Not applicable.

\section{Competing interests}

The authors declare that they have no competing interests.

\section{Author details}

${ }^{1}$ Hospital Israelita Albert Einstein, São Paulo, Brazil. Instituto de Psiquiatria, Hospital das Clínicas da Faculdade de Medicina da USP, Rua Joaquim Eugênio de Lima, 881 cj 708, Sao Paulo, SP, Brazil. Faculdade de Medicina do Hospital Israelita Albert Einstein, São Paulo, Brazil. ${ }^{3}$ Instituto de Psiquiatria, Hospital das Clínicas da Faculdade de Medicina da USP, Sao Paulo, Brazil. ${ }^{4}$ Universidade Federal do Piauí, Disciplina de Neurologia, Teresina, PI, Brazil.

\section{Received: 2 May 2019 Accepted: 7 August 2019}

Published online: 15 August 2019

\section{References}

1. World Health Organization (WHO) (2011) Atlas of headache disorders and resources in the world 2011. http://www.who.int/mental_health/ management/atlas_headache_disorders/en/

2. Woldeamanuel YW, Cowan RP (2017) Migraine affects 1 in 10 people worldwide featuring recent rise: a systematic review and meta-analysis of community-based studies involving 6 million participants. J Neurol Sci 372 307-315 https://doi.org/10.1016/j.jns.2016.11.071
3. Queiroz LP, Silva Junior AA (2015) The prevalence and impact of headache in Brazil. Headache 55:32-38 https://doi.org/10.1111/head.12511

4. Robertson CE, Garza I (2012) Critical analysis of the use of onabotulinumtoxinA (botulinum toxin type a) in migraine. Neuropsychiatr Dis Treat 8:35-48

5. Lipton RB (2009) Tracing transformation: chronic migraine classification, progression, and epidemiology. Neurology 72:S3-S7 https://doi.org/10.1212/ WNL.0b013e3181974b19

6. Weatherall MW (2015) The diagnosis and treatment of chronic migraine. Ther Adv Chronic Dis 6:115-123 https://doi.org/10.1177/2040622315579627

7. Headache Classification Committee of the International Headache Society (IHS) (2013) The international classification of headache disorders, 3rd edition (beta version). Cephalalgia 33:629-808 https://doi.org/10.1177/03331 02413485658

8. Blumenfeld A, Varon S, Wilcox T, Buse D, Kawata A, Manack A et al (2010) Disability, HRQoL and resource use among chronic and episodic migraineurs: results from the international burden of migraine study (IBMS). Cephalalgia 31:301-315 https://doi.org/10.1177/0333102410381145

9. Lipton RB, Stewart WF, Von Korff M (1995) Migraine impact and functional disability. Cephalalgia 15(Suppl 1):4-9 https://doi.org/10.1111/J.1468-2982.1 995.TB00041.X

10. Rasmussen BK, Jensen R, Olesen J (1992) Impact of headache on sickness absence and utilisation of medical services: a Danish population study. J Epidemiol Community Health 46:443-446

11. Doyle C, Lennox L, Bell D (2013) A systematic review of evidence on the links between patient experience and clinical safety and effectiveness. BMJ Open 3:e001570 https://doi.org/10.1136/bmjopen-2012-001570

12. Leonardi M, Ruiz De La Torre E, Steiner TJ, Tinelli M, Raggi A, D’Amico D et al (2018) Value of treatment of headache patients and need to improve headache patients' journey. Neurol Sci 39:115-116 https://doi.org/10.1007/ s10072-018-3366-6

13. Davies PTG, Lane RJM, Astbury T, Fontebasso M, Murphy J, Matharu M (2019) The long and winding road: the journey taken by headache sufferers in search of help. Prim Health Care Res Dev 20:e4 https://doi.org/10.1017/ S1463423618000324

14. Cevoli S, D'amico D, Martelletti P, Valguarnera F, Del Bene E, De Simone R et al (2009) Underdiagnosis and undertreatment of migraine in Italy: a survey of patients attending for the first time 10 headache centres. Cephalalgia 29: 1285-1293 https://doi.org/10.1111/j.1468-2982.2009.01874.x

15. Santos IS, Tavares BF, Munhoz TN, de Almeida LSP, da Silva NTB, Tams BD et al (2013) Sensibilidade e especificidade do Patient Health Questionnaire-9 (PHQ-9) entre adultos da população geral. Cad Saude Publica 29:1533-1543 https://doi.org/10.1590/0102-311X00144612

16. Ruiz MA, Zamorano E, García-Campayo J, Pardo A, Freire O, Rejas J (2011) Validity of the GAD-7 scale as an outcome measure of disability in patients with generalized anxiety disorders in primary care. J Affect Disord 128:277286 https://doi.org/10.1016/j.jad.2010.07.010

17. Burch R (2019) Migraine and tension-type headache. Med Clin North Am 103:215-233 https://doi.org/10.1016/j.mcna.2018.10.003

18. British Association for the study of headache (2010) Guidelines for all healthcare professionals in the ontents. Management:1-53

19. National Institute for Health and Care Excellence (2012) Headaches: diagnosis and management of headaches in young people and adults. NICE Guidel 1 https://doi.org/10.1136/bmj.e5765

20. Viana M, Sances G, Terrazzino S, Sprenger T, Nappi G, Tassorelli C (2018) When cervical pain is actually migraine: an observational study in 207 patients. Cephalalgia 38:383-388 https://doi.org/10.1177/0333102416683917

21. Giacomozzi ARE, Vindas AP, Da Silva AA, Bordini CA, Buonanotte CF, De Paula Roesier CA et al (2013) Latin American consensus on guidelines for chronic migraine treatment. Arq Neuropsiquiatr 71:478-486 https://doi. org/10.1590/0004-282X20130066

22. Yang CP, Chang MH, Liu PE, Li TC, Hsieh CL, Hwang KL et al (2011) Acupuncture versus topiramate in chronic migraine prophylaxis: a randomized clinical trial. Cephalalgia 31:1510-1521 https://doi.org/10.1177/ 0333102411420585

23. Vincent MB, de Carvalho JJ (1999) Primary headache care delivery by nonspecialists in Brazil. Brazilian headache care cooperative group. Cephalalgia:520-524 https://doi.org/10.1046/j.1468-2982.1999.019005520x

24. Peres MFP, Silberstein S, Moreira F, Corchs F, Vieira DS, Abraham $N$ et al (2007) Patients' preference for migraine preventive therapy. Headache 47: 540-545 https://doi.org/10.1111/j.1526-4610.2007.00757.x 
25. Messali A, Sanderson JC, Blumenfeld AM, Goadsby PJ, Buse DC, Varon SF et al (2016) Direct and indirect costs of chronic and episodic migraine in the United States: a web-based survey. Headache 56:306-322 https://doi.org/1 $0.1111 /$ head. 12755

26. Peres MFP, Mercante JPP, Tobo PR, Kamei H, Bigal ME (2017) Anxiety and depression symptoms and migraine: a symptom-based approach research. J Headache Pain 18:1-8 https://doi.org/10.1186/s10194-017-0742-1

27. Santos IS, Brunoni AR, Goulart AC, Griep RH, Lotufo PA, Benseñor IM (2014) Negative life events and migraine: a cross-sectional analysis of the Brazilian longitudinal study of adult health (ELSA-Brasil) baseline data. BMC Public Health 14:1-10 https://doi.org/10.1186/1471-2458-14-678

28. European Headache Federation (2010) Princípios europeus da abordagem das cefaleias comuns nos cuidados de saúde primários. Headache

\section{Publisher's Note}

Springer Nature remains neutral with regard to jurisdictional claims in published maps and institutional affiliations.

Ready to submit your research? Choose BMC and benefit from:

- fast, convenient online submission

- thorough peer review by experienced researchers in your field

- rapid publication on acceptance

- support for research data, including large and complex data types

- gold Open Access which fosters wider collaboration and increased citations

- maximum visibility for your research: over $100 \mathrm{M}$ website views per year

At BMC, research is always in progress.

Learn more biomedcentral.com/submissions 